\title{
Impact of Pediatric Dentistry Residents Posted in Pediatrics Department: A Retrospective Assessment of 6 Years
}

\author{
Anusha Mohan ${ }^{1}$, Muthu MS², Padmanabhan Ramachandran ${ }^{3}$, Padmasani V Ramanan $^{4}$, Selvakumaar Haridoss ${ }^{5}$, \\ Kavitha Swaminathan ${ }^{6}$, Subbalekshmi Natesh ${ }^{7}$
}

\begin{abstract}
Aim: To measure the influence of rotatory pediatrics postings for dental residents on the outpatient census of the pediatric dentistry department. The secondary aims were to assess the change in trend toward the number of preschool children visiting the department before and after the initiation of pediatrics posting and also to find the percentage of children affected with caries among children visiting the pediatricians.

Materials and methods: Retrospectively, the census of the pediatric dentistry department was calculated from 2010 to 2016 . The number of preschool children who visited the pediatric dentistry department during this period was determined. From the pediatrics posting records, the dental status of the children, the number screened, the number referred, and the number reported to dentistry following referral were tabulated. Descriptive statistics and Chi-square tests were performed.

Results: After the initiation of pediatrics postings for residents, the outpatient census has increased by $26 \%$. There was a significant increase in the number of preschool children visiting the pediatric dentist. About $57.09 \%$ of children screened in the pediatrics department had dental disease.

Conclusion: There is an increase in the patient flow of the pediatric dentistry department with a greater number of preschool children visiting the pediatric dentist after initiation of the pediatrics postings for residents. More than half the children visiting pediatricians had dental disease requiring professional care.

Clinical significance: Pediatrics postings for residents can be used in teaching centers as an opportunity to spread awareness and increase the number of preschool children visiting pediatric dentists, thereby increasing prevention and early intervention of early childhood caries.
\end{abstract}

Keywords: Children, Early childhood caries, Pediatrician, Prevention, Tooth decay.

International Journal of Clinical Pediatric Dentistry (2021): 10.5005/jp-journals-10005-1890

\section{INTRODUCTION}

A child is first seen early in life by a gynecologist and a pediatrician. ${ }^{1}$ The child's mother is counseled by these two professionals regarding feeding practices, nutrition, and immunization. The importance of an early dental visit, however, is frequently neglected. ${ }^{1}$ This neglect often leads to the most common chronic disease affecting the oral cavity-Early Childhood Caries (ECC). To prevent this disease, the American Academy of Pediatric Dentistry and the American Academy of Pediatrics recommend early dental visits, as soon as the first tooth erupts into the oral cavity or at least by 12 months of age. ${ }^{2}$ Despite these recommendations and guidelines, it should be noted that, in most cases, a child is brought to the dental office for the first time when there is a visible caries lesion or dental trauma has occurred. ${ }^{3,4}$ This is mainly attributed to the parent's or caregiver's inability to identify early caries lesions at a young age $^{5}$ and also due to the common perception that the primary (milk) teeth will be replaced.

Very young children are often brought to the pediatrician for a well-baby check-up, making it easier to reach these young children. The importance of oral health in the early years of life has been well-documented. ${ }^{6-8}$ Earlier reports have shown that preventive services are not adequately utilized by young children., ${ }^{9,10}$ The medical and dental professions have realized the importance of physicians and pediatricians in the prevention of ECC and have taken steps to promote their involvement. ${ }^{11}$ The pediatricians believe that their role is crucial in identifying the children at risk of developing dental diseases. ${ }^{12}$ Surveys indicate that physicians are even ready to administer preventive dental care to their young patients. ${ }^{12}$ These specialists must have good knowledge about ECC and its overall
1,5,6 Department of Pedodontics and Preventive Dentistry, Sri Ramachandra Faculty of Dental Sciences, Sri Ramachandra Institute of Higher Education and Research, Chennai, Tamil Nadu, India

${ }^{2}$ Department of Pedodontics and Preventive Dentistry, Sri Ramachandra Faculty of Dental Sciences, Sri Ramachandra Institute of Higher Education and Research, Chennai, Tamil Nadu, India; Centre of Medical and Bio-Allied Health Sciences Research, Ajman University, United Arab Emirates

${ }^{3,4}$ Department of Pediatrics, Sri Ramachandra Faculty of Dental Sciences, Sri Ramachandra Institute of Higher Education and Research, Chennai, Tamil Nadu, India

${ }^{7}$ Department of Pedodontics and Preventive Dentistry, Pushpagiri College of Dental Sciences, Thiruvalla, Kerala, India

Corresponding Author: Muthu MS, Department of Pedodontics and Preventive Dentistry, Sri Ramachandra Faculty of Dental Sciences, Sri Ramachandra Institute of Higher Education and Research, Chennai, Tamil Nadu, India; Centre of Medical and Bio-Allied Health Sciences Research, Ajman University, United Arab Emirates, Phone: +91 9444045094, e-mail: muthumurugan@gmail.com

How to cite this article: Mohan A, Muthu MS, Ramachandran P, et al. Impact of Pediatric Dentistry Residents Posted in Pediatrics Department: A Retrospective Assessment of 6 Years. Int J Clin Pediatr Dent 2021;14(1):84-87.

Source of support: Nil

Conflict of interest: None

impact on the general quality of life. The pediatric dentists must impart this knowledge among other specialists and also to the children's caregivers by closely working with them as a team. This 
can be achieved by adopting a multidisciplinary approach in which pediatric dentists should be a part of the team that provides overall healthcare to children. Although the benefit of an interdisciplinary approach has been established long ago, there is a lack of scientific evidence to prove that the medical and dental pediatric specialties can bring about a change in this trend by working as a team. Pediatric postings for pediatric dentistry residents pave the way to establishing interprofessional care through the concept of an interdisciplinary approach.

The primary aim of the present investigation was to measure the influence of pediatric postings for residents (pediatric dentistry) in the patient flow of the pediatric dentistry department. The two secondary aims were to assess the changing trend toward the number of preschool children visiting the department of pediatric dentistry after the initiation of rotating pediatric postings for the pediatric dentistry residents, and also to see the percentages of children affected with dental disease among the children screened in the outpatient department of pediatrics.

\section{Materials and Methods}

\section{Ethical Approval}

The study was carried out in a university dental hospital. Institutional ethical approval was obtained.

\section{Preparation for Pediatrics Posting}

To adopt a multidisciplinary approach to prevent ECC, six pediatric dentistry residents of the university were given postings in the Department of Pediatrics on rotation every 2 weeks during their 3-year residency program. The residents were given prior training in age-specific infant oral healthcare measures, anticipatory guidance, diet counseling, and brushing instructions for all age groups of children anticipated in the pediatrics department. Group discussions, demonstrations, and question-and-answer sessions on these topics were conducted with experienced faculty. They were also asked to conduct didactic presentations on anticipatory guidance and infant oral health, to ensure that they had adequate knowledge regarding the same. Following this, scheduled postings were given to each resident in rotation.

\section{Description of Pediatrics Posting}

This posting was incorporated as a part of the pediatric dental residency program from August 2013. Previously, this posting was attended by one predoctoral student (on rotation every day) during the compulsory rotating internship. Later, when the residents started attending this posting in 2013, the student in an internship was still available to assist the pediatric dental residents during the postings. Together, they screened and recorded the oral health of the child visiting the pediatrics department. The resident and the intern were available in the pediatrics department on all working days (Monday to Saturday) from 8 a.m. to 12 noon. The main aim of the resident visiting the Department of Pediatrics was to provide age-specific anticipatory guidance, brushing instructions, and diet counseling to the caregivers and children visiting the outpatient clinic of the pediatrics department. Children requiring dental treatment were referred to the pediatric dental department and were provided with the necessary treatment. Parents of newborns and infants were given anticipatory guidance with an emphasis on the importance of establishing a dental home by 6 months of age. Children with acute medical conditions making oral examination difficult in the outpatient setting were referred to visit the pediatric dental department after the acute phase subsided.

\section{Data Collection}

Retrospectively, the outpatient census of the department of pediatric dentistry was calculated for a period between 2011 and 2016. The pediatrics postings for pediatric dental residents were initiated in August 2013; hence, data from 2010 to 2013 were collected to determine the census 3 years before the postings, and data from 2013 to 2016 were collected to determine the census 3 years after the postings. The number of young children ( $<6$ years of age) who visited the pediatric dentistry department 3 years before and 3 years after the pediatrics postings for the residents was calculated. From the records of the residents and the department, the number of patients screened in the pediatrics department, the number of patients referred from the pediatrics department, and the number of patients who reported back following referral were also tabulated.

\section{Data Analysis}

A descriptive statistics approach was used to calculate the patient flow of the pediatric dentistry department before and after the initiation of pediatrics postings for the residents. The percentage of children visiting the pediatrics department and requiring dental treatment and the percentage of children who reported back to the pediatric dental department following referral were calculated. The Chi-square test was used to check whether the increase in patient flow was associated with the initiation of pediatrics postings for the residents.

\section{Results}

There was a sudden increase in the outpatient flow of the pediatric dental department after the pediatrics posting for the residents was initiated in the year 2013 (Table 1). The average growth rate of the patient flow in the department had been from 10 to $15 \%$ every year. In 2013, the growth rate was $26 \%$. A Chi-square test was used to compare the association between the number of preschool children visiting the department before and after the pediatric posting was initiated. Statistical analysis showed a Chi-square statistic of 285.2243 , with a $p$ value of 0.0001 , which is statistically significant (Table 2). Hence, the increase in the number of preschool children visiting the department was significantly associated with the commencement of the pediatrics posting.

During the pediatrics postings from August 2013 to July 2016, 5,559 children were screened by the residents. Of these, 3,174 children had some form of dental disease requiring treatment. This shows that $57.09 \%$ of children seen at the department of pediatrics had a dental disease that required specialist care. Of the

Table 1: Outpatient flow of patients in the department of pediatric dentistry

\begin{tabular}{llll}
\hline & $\begin{array}{l}\text { No. of boys } \\
\text { reporting to } \\
\text { the outpatient } \\
\text { department of } \\
\text { pediatric dentistry }\end{array}$ & $\begin{array}{l}\text { No. of girls } \\
\text { reporting to } \\
\text { the outpatient } \\
\text { department of } \\
\text { pediatric dentistry }\end{array}$ & $\begin{array}{l}\text { Total no. of } \\
\text { children reporting } \\
\text { to the outpatient } \\
\text { department of } \\
\text { pediatric dentistry }\end{array}$ \\
\hline 2010 & 1,791 & 1,689 & 3,480 \\
2011 & 2,111 & 1,979 & 4,090 \\
2012 & 3,026 & 2,721 & 5,747 \\
2013 & 4,119 & 3,716 & 7,835 \\
2014 & 4,457 & 3,551 & 8,008 \\
2015 & 4,729 & 4,050 & 8,779 \\
2016 & 5,995 & 4,871 & 10,866 \\
\hline
\end{tabular}


Table 2: Outpatient profile of patients before and after initiation of pediatrics postings for the graduate students

\begin{tabular}{|c|c|c|c|c|c|c|}
\hline \multirow[b]{2}{*}{ S. no. } & \multirow[b]{2}{*}{ Year } & \multirow[b]{2}{*}{ Status } & \multicolumn{2}{|c|}{$\begin{array}{c}\text { Outpatients in pediatric } \\
\text { dentistry department }\end{array}$} & \multirow[b]{2}{*}{ Total } & \multirow[b]{2}{*}{ Chi-square statistic } \\
\hline & & & Age & Number & & \\
\hline \multirow[t]{2}{*}{1} & August 2010 to July 2013 & Before pediatrics posting & $<6$ & 2,010 & 6,330 & 285.2243 \\
\hline & & & $>6$ & 4,320 & & \\
\hline \multirow[t]{2}{*}{2} & August 2013 to July 2016 & After pediatrics posting & $<6$ & 6,902 & 15,649 & \\
\hline & & & $>6$ & 8,747 & & \\
\hline
\end{tabular}

$p=0.00001$

3,174 children who were referred to the department of pediatric dentistry, 1,355 children (42.69\%) had reported to the department to avail themselves of the required dental care.

\section{Discussion}

Awareness about guidelines and positive attitudes toward oral health are important factors in improving oral healthcare for infants and toddlers. ${ }^{13,14}$ This retrospective analysis of the data showed that there was a significant increase in the outpatient flow of the department of pediatric dentistry following the initiation of pediatrics postings for the residents. This could be due to the increased awareness created by the residents among parents regarding oral hygiene and dental disease, which made the parents bring their children for dental visits. The postings were planned in such a way that the residents had prior training to instill this awareness in the parents through proper delivery of anticipatory guidance and counseling.

The results also showed that there was a significant increase in the number of patients $<6$ years of age reporting to the department of pediatric dentistry after the initiation of the postings. The anticipatory guidance provided by the residents could have influenced the parents to bring their younger children for dental visits at an early age. Previous studies have shown that children under 6 years of age had less than half the number of dental visits compared with children $>6$ years of age.${ }^{15}$ It was found that by age 1 , only $2 \%$ of the children had a dental visit. ${ }^{16}$ Lack of an established dental home by age 1 has been reported by dentists as the most common barrier in providing infant oral examinations, which enforces the need to educate parents regarding the importance of the first dental visit. ${ }^{17}$ Given these facts, the increased numbers of children visiting pediatric dentists $<6$ years of age indicate that there is an increased opportunity to provide more preventive care to this age group of patients.

It was observed in the study that $57.09 \%$ of children visiting the pediatricians had some form of dental disease requiring specialist care. Early diagnosis and preventive care can save millions of dollars every year spent on providing treatment for established ECC in very young children. Studies have also shown the cost-effectiveness of early intervention in medicine. ${ }^{18-20}$ There is a need to improve the measures taken to increase referrals that may be important to treat existing disease and promote adequate oral healthcare. ${ }^{21,22}$ To identify children with dental disease and treat them early, an association or collaboration between medical and dental departments is important, since more physicians deliver preventive services. ${ }^{10,23}$ In a university environment with both medical and dental schools attached, there is an increased opportunity to promote interprofessional collaboration and improve referrals.

The results of this survey prove that pediatrics postings for residents have improved the outpatient flow in the pediatric dentistry department. In particular, the number of patients $<6$ years of age has increased, which partially fulfills the goal of providing early oral healthcare to children visiting pediatricians. Doing this in a medical setting allows the residents to interact with their counterparts in the pediatrics specialty, ensuring that the pediatricians are sensitized to the oral healthcare needs of their patients and can refer them to a pediatric dentist. The residents provided anticipatory guidance and brushing instructions to the children in front of the pediatricians, which ensured that the pediatricians are also aware of the oral health advice provided to their patients and helped them to provide the same advice in the absence of the residents. It also helped the dentists to gain knowledge regarding the child's medical condition and the current treatment that the child is undergoing. Reports like this prove that it will be beneficial if early dental screening, like vaccination schedules, can be made mandatory for children, so that prevention, early diagnosis, and treatment can be successfully achieved in the pediatric community.

\section{Conclusion}

The survey concludes that there is increased outpatient flow in the pediatric dentistry department after the initiation of pediatrics postings for the residents. It was also found that there was a significant increase in the number of patients $<6$ years of age reporting for their first dental visit after the postings were initiated for the residents. The authors also observed that about $57.09 \%$ of children visiting the pediatrician had dental disease. It could be concluded that such postings can be initiated for residents in universities with attached medical and dental colleges so that there is good interprofessional care with increased strategies to provide preventive measures.

\section{ACKNOWLEDGMENTS}

The authors provide special thanks to Dr Narrentharan, Dr Niveditha, Dr Ankita, Dr Jean Aishwarya, Dr Priya, Dr Naveen Raj, Dr Kota Bala, and Dr Pavani, for screening the patients at the pediatrics outpatient department.

\section{References}

1. Subramaniam P, Babu KLG, Babu PS, et al. Oral health care of children: gynecologists and pediatricians' perspective. J Clin Pediatr Dent 2008;32(3):253-258. DOI: 10.17796/jcpd.32.3.8543017407g46h53.

2. Chung MH, Kaste LM, Koerber A, et al. Dental and medical students' knowledge and opinions of infant oral health. J Dent Educ 2006;70(5):511-517. DOI: 10.1002/j.0022-0337.2006.70.5.tb04105.x.

3. Camargo MBJ, Barros AJD, Frazão $P$, et al. Predictors of dental visits for routine check-ups and for the resolution of problems among 
preschool children. Rev Saude Publica 2012;46(1):87-97. DOI: 10.1590/ s0034-89102012005000004.

4. Zink AG, Molina EC, Diniz MB, et al. Communication application for use during the first dental visit for children and adolescents with autism spectrum disorders. Pediatr Dent 2018;40(1):18-22.

5. Divaris K, Vann WF, Baker AD, et al. Examining the accuracy of caregivers' assessments of young children's oral health status. J Am Dent Assoc 2012;143(11):1237-1247. DOI: 10.14219/jada. archive.2012.0071.

6. Bhaskar V, McGraw KA, Divaris K. The importance of preventive dental visits from a young age: systematic review and current perspectives. Clin Cosmet Investig Dent 2014;6:21-27. DOI: 10.2147/CCIDE. S41499.

7. Petersen PE. The World Oral Health Report 2003: continuous improvement of oral health in the 21st century-the approach of the WHO global oral health programme. Community Dent Oral Epidemiol 2003;3(1):3-23. DOI: 10.1046/j.2003.com122.x.

8. Edelstein BL. The dental caries pandemic and disparities problem. BMC Oral Health 2006;6(1):S2. DOI: 10.1186/1472-6831-6-S1-S2.

9. Mouradian WE, Wehr E, Crall JJ. Disparities in children's oral health and access to dental care. JAMA 2000;284(20):2625-2631. DOI: 10.1001/ jama.284.20.2625.

10. Lewis CW, Johnston BD, Linsenmeyar KA, et al. Preventive dental care for children in the United States: a national perspective. Pediatrics 2007;119(3):e544-e553. DOI: 10.1542/peds.2006-1958.

11. Pierce KM, Rozier RG, Vann WF. Accuracy of pediatric primary care providers' screening and referral for early childhood caries. Pediatrics 2002;109(5):E82-E82. DOI: 10.1542/peds.109.5.e82.

12. Lewis CW, Grossman DC, Domoto PK, et al. The role of the pediatrician in the oral health of children: a national survey. Pediatrics 2000;106(6):E84. DOI: 10.1542/peds.106.6.e84.

13. Reilly JJ, Kelly J. Long-term impact of overweight and obesity in childhood and adolescence on morbidity and premature mortality in adulthood: systematic review. Int J Obes 2011;35(7):891-898. DOI: 10.1038/ijo.2010.222.
14. Mobley C, Marshall TA, Milgrom P, et al. The contribution of dietary factors to dental caries and disparities in caries. Acad Pediatr 2009;9(6):410-414. DOI: 10.1016/j.acap.2009.09.008.

15. Edelstein BL, Manski RJ, Moeller JF. Pediatric dental visits during 1996: an analysis of the federal medical expenditure panel survey. Pediatr Dent 2000;22(1):17-20.

16. Slayton RL, Warren JJ, Levy SM, et al. Frequency of reported dental visits and professional fluoride applications in a cohort of children followed from birth to age 3 years. Pediatr Dent 2002;24(1):64-68.

17. McLoyd VC, Jayaratne TE, Ceballo R, et al. Unemployment and work interruption among African American single mothers: effects on parenting and adolescent socioemotional functioning. Child Dev 1994;65(2):562-589. DOI: 10.2307/1131402.

18. Van Allen Ml, Fraser FC, Dallaire L, et al. Recommendations on the use of folic acid supplementation to prevent the recurrence of neural tube defects. Clinical Teratology Committee, Canadian College of Medical Geneticists. CMAJ 1993;149(9):1239-1243.

19. Pham CT, Karnon JD, Middleton PF, et al. Randomised clinical trials in perinatal health care: a cost-effective investment. Med J Aust 2017;207(7):289-293. DOI: 10.5694/mja16.01178.

20. Svefors P, Selling KE, Shaheen R, et al. Cost-effectiveness of prenatal food and micronutrient interventions on under-five mortality and stunting: analysis of data from the MINIMat randomized trial, Bangladesh. PLoS ONE 2018;13(2):e0191260. DOI: 10.1371/journal. pone. 0191260

21. Malcheff S, Pink TC, Sohn W, et al. Infant oral health examinations: pediatric dentists' professional behavior and attitudes. Pediatr Dent 2009;31(3):202-209. DOI: 10.1308/135576109789389388.

22. Seale NS, Casamassimo PS. Access to dental care for children in the United States: a survey of general practitioners. J Am Dent Assoc 2003;134(12):1630-1640. DOI: 10.14219/jada.archive.2003.0110.

23. Hale KJ. American Academy of Pediatrics Section on pediatric dentistry. Oral health risk assessment timing and establishment of the dental home. Pediatrics 2003;111(5):1113-1116. DOI: 10.1542/ peds.111.5.1113. 